\title{
Isolasi dan Identifikasi Senyawa Seskuiterpen dari Curcuma soloensis Val. (Temu Glenyeh)
}

\section{Soerya Dewi Marliyana, Muhamad Widyo Wartono, Fajar Rakhman Wibowo, Gesti Munasah}

Prodi Kimia, Fakultas Matematika dan Ilmu Pengetahuan Alam, Universitas Sebelas Maret, Jl. Ir. Sutami 36 A, Surakarta 57126, Indonesia

Email: msoerya@staff.uns.ac.id

Received: March 2018; Revised: August 2018; Accepted: October 2018; Available Online: November 2018

\begin{abstract}
Abstrak
Curcuma soloensis Val. merupakan tanaman famili Zingiberaceae dan dikenal dengan nama temu glenyeh. Tanaman ini telah dimanfaatkan sebagai tanaman obat tetapi belum banyak dilaporkan tentang komponen kimianya. Oleh karena itu tujuan dari penelitian ini adalah mengisolasi dan mengidentifikasi komponen kimia dari rimpang C. soloensis Val. Isolasi dilakukan dengan ekstraksi (Soxhlet), fraksinasi dan purifikasi. Fraksinasi dan purifikasi dilakukan dengan menggunakan metode kromatografi. Identifikasi struktur ditentukan dengan metode spektroskopi yang meliputi 1D-NMR $\left({ }^{1} \mathrm{H}\right.$ NMR, ${ }^{13} \mathrm{C}$ NMR) dan 2D-NMR (HMQC, HMBC). Berdasarkan analisis data spektra NMR dan dibandingkan dengan data literatur, senyawa yang diperoleh berbentuk cair berwarna kuning adalah suatu sesquiterpen yaitu ar-turmeron (2-metil-6-(4-metilfenil)hept-2-en4-on). Ar-turmerone pertama kali ditemukan dari rimpang Curcuma soloensis Val.
\end{abstract}

Kata kunci: Ar-turmeron, Curcuma soloensis Val, seskuiterpen

\begin{abstract}
Curcuma soloensis Val. is a family plant Zingiberaceae and is known as "temu gelnyeh". This plant has been used as a medicinal plant but has not been widely reported about its chemical components. Therefore, this study was carried out to isolation and identification of the chemical components of the C. soloensis Val. rhizome. Isolation was done by extraction, fractionation, and purification. The fractionation and purification of the compound were carried out using chromatography methods. The identification of the compound was determined by spectroscopic methods including 1D-NMR ( ${ }^{1} \mathrm{H}$ NMR, ${ }^{13} \mathrm{C}$ NMR) and 2D-NMR (HSQC, HMBC). Based on NMR spectra data analysis and compared with literature, the compound obtained yellow liquid was ar-turmerone (2-methyl-6- (4-methylphenyl) hept-2-en-4-on) which was a terpenoid sesquiterpene. Ar-turmerone is the first compound that found from Curcuma soloensis Val. rhizome.
\end{abstract}

Keywords: Ar-turmerone, Curcuma soloensis Val., sesquiterpene.

DOI: http://10.15408/jkv.v4i2.7443

\section{PENDAHULUAN}

Negara Indonesia mempunyai sumber alam hayati yang luar biasa dan sudah dimanfaatkan diberbagai bidang, salah satunya adalah sebagai obat tradisional. Tanaman yang dimanfaatkan sebagai obat di Indonesia umumnya dari jenis temu-temuan (rimpang), seperti dalam famili Zingiberaceae. Salah satu genus dalam famili tersebut adalah Curcuma. Genus Curcuma telah dilaporkan mempunyai berbagai bioaktivitas antara lain sebagai antioksidan (Caiqin et al., 2018), antiinflamatori (Yuan et al., 2017), antimicrobial (Pulido-Moran et al., 2016), antiarthritik, antidepresan, antiatherosklerotik, antiaging (Nelson et al., 2017), antidiabetik 
(Kato et al., 2017) dan antikanker (Naksuriya et al., 2014).

Metabolit sekunder yang dilaporkan telah berhasil diisolasi dari genus Curcuma adalah golongan kurkuminoid antara lain kurkumin, demetoksikurkumin, dan bisdemetoksi-kurkumin (Asghari et al., 2009; Lateef et al., 2016; Wikara et al., 2016). Selain itu juga golongan terpenoid yaitu monoterpen seperti 1.8-sineol dan sesquiterpen antara lain germakron, kurzerenon, (Theanphong et al., 2015; Simoh and Zainal, 2015), ar-turmeron, $\beta$-sesquifelandren (Lateef et al., 2016), kurkuminol, ar-kurkumin (Halim et al, 2012) dan xantorizol (Mangunwardoyo et al., 2012; Jantan et al., 2012).

Temu glenyeh (C. soloensis Val.) merupakan salah satu spesies dari genus Curcuma. Penelusuran literatur memperlihatkan bahwa kandungan metabolit sekunder dari tumbuhan $C$. soloensis Val. belum banyak dilaporkan. Laporan metabolit sekunder dari spesies ini sejauh ini lebih banyak mengenai kandungan minyak atsirinya (Shibuya, et al., 1999), sedangkan kandungan non-atsirinya yang dilaporkan diperoleh dari rimpang tanaman ini adalah, senyawa kurkumin dan bisacuron (Vitasari et al., 2016).

Mengingat belum banyak komponen kimia non-atsiri yang berhasil diisolasi dan potensi dari $C$. soloensis Val. untuk dijadikan tanaman obat maka penelitian tentang isolasi dan identifikasi komponen kimia tanaman ini masih perlu dilakukan. Hasil penelitian ini dapat menambah database senyawa dalam ekstrak C. soloensis Val. yang selanjutnya dapat dimanfaatkan sebagai sumber senyawa obat.

\section{METODE PENELITIAN}

\section{Alat dan Bahan}

Peralatan yang digunakan peralatan gelas, rotary evaporator, lampu UV 254 nm, spektrofotometer Agilent NMR 400 $\mathrm{MHz}$ dan peralatan gelas. Bahan tumbuhan yang digunakan adalah rimpang temu glenyeh (C. soloensis Val.) yang telah dikeringkan dari daerah Boyolali, Jawa Tengah dan diidentifikasi oleh staff laboratorium taksonomi Biologi FMIPA UNS (145/UN27.9.6.4/Lab). N-heksan, etil asetat, metanol, aseton dan kloroform dengan kualitas re-destilasi. Silika gel 60
$\mathrm{PF}_{254}$ (Merck), Silika gel 60 (0.04-0.063 mm) 230-400 mesh ASTM (Merck), Silika gel $60 \mathrm{~F}_{254} 0.25 \mathrm{~mm}$ (Merck) (KLT) dan Silika gel $60 \quad(0.2-0.5 \mathrm{~mm})$ (Merck). Pereaksi penampak noda $\mathrm{CeSO}_{4}$ (Merck).

\section{Ekstraksi dan Isolasi}

Serbuk kering rimpang $C$. soloensis Val. sebanyak $1.16 \mathrm{~kg}$ diekstraksi Soxhlet dengan pelarut aseton sebanyak $2.2 \mathrm{~L}$ selama 18 jam. Masing-masing ekstraksi dilakukan 25 kali sirkulasi dengan jumlah sampel $\pm 50 \mathrm{~g}$. Filtrat yang diperoleh dievaporasi sampai pekat hingga dihasilkan ekstrak aseton.

Ekstrak aseton (20 g) selanjutnya difraksinasi dengan Kromatografi Vakum Cair (KVC), menggunakan eluen $n$-heksana : EtOAc yang kepolarannya di tingkatkan secara gradual mulai dari 100\%:0\%; 90\%:10\%; 80\%:20\%; 70\%:30\%; 60\%:40\%; 50\%:50\%; 40\%:60\%; 0\%:100\% menghasilkan 19 fraksi (F1-F19). Fraksi F2 dan F3 selanjutnya digabungkan, kemudian dipisahkan lebih lanjut dengan teknik kromatografi kolom tekan menggunakan campuran eluen $n$-heksana dan etil asetat (9.5:0.5 s/d 8:2) menghasilkan 27 fraksi. Berdasrkan hasil analisis menggunakan KLT, maka fraksi ke-3 dari proses farksinasi ini sudah berupa isolat murni yang berwujud cairan berwarna kekuningan sebanyak $20 \mathrm{mg}$ (1). Isolat murni (1) selanjutnya dikarakterisasi rumus strukturnya menggunakan metode spektroskopi, yang meliputi NMR $1 \mathrm{D}\left({ }^{1} \mathrm{H}\right.$ dan ${ }^{13} \mathrm{C}$ ), NMR 2D (HSQC dan HMBC).

\section{HASIL DAN PEMBAHASAN Isolasi dan Identifikasi Senyawa Murni}

Isolasi komponen kimia rimpang $C$. soloensis Val. dengan dengan cara soxhletasi dengan pelarut aseton sehingga diperoleh ekstrak aseton. Selanjutnya, terhadap ekstrak tersebut dilakukan proses pemisahan dan pemurnian dengan menggunakan berbagai teknik kromatografi seperti, KCV, KKT, dan KLT sehingga diperoleh isolat murni (1).

Spektrum $\quad{ }^{1} \mathrm{H}-\mathrm{NMR} \quad(400 \mathrm{MHz}$, $\mathrm{CDCl} 3)$ menunjukkan terdapat sinyal proton aromatis pada geseran kimia $\left(\delta_{\mathrm{H}}\right) 7.13 \mathrm{ppm}(m$, $4 \mathrm{H})$. Selain itu, adanya sinyal proton metin vinil ditunjukkan oleh $\delta_{\mathrm{H}} 6.05 \mathrm{ppm}(s, 1 \mathrm{H})$ yaitu metin yang terikat pada atom $\mathrm{C}$ alkena, sedangkan pada $\delta_{\mathrm{H}} 3.30 \mathrm{ppm} \quad(m, 1 \mathrm{H})$ merupakan gugus metin yang terikat pada atom $\mathrm{C}$ alkana. Sinyal proton metilen $\left(\mathrm{CH}_{2}\right)$ 
ditunjukkan oleh $\delta_{\mathrm{H}} 2.66 \mathrm{ppm}(d d, 2 \mathrm{H}, J=6.05$; $15.70 \mathrm{~Hz})$. Untuk proton metil $\left(\mathrm{CH}_{3}\right)$ ditunjukkan oleh sinyal proton pada $\delta_{\mathrm{H}} 2.33$ $\operatorname{ppm}(s, 3 \mathrm{H}), \delta_{\mathrm{H}} 2.13 \mathrm{ppm}(s, 3 \mathrm{H}), \delta_{\mathrm{H}} 1.88 \mathrm{ppm}$ $(s, 3 \mathrm{H})$ dan $\delta_{\mathrm{H}} 1.27 \mathrm{ppm}(d, 3 \mathrm{H}, J=7,0 \mathrm{~Hz})$. Sedangkan dari data spektrum ${ }^{13} \mathrm{C}$ NMR (100 $\left.\mathrm{MHz}, \mathrm{CDCl}_{3}\right)$ memperlihatkan adanya 15 sinyal karbon yaitu 6 sinyal karbon alifatik (C$\left.s p^{3}\right)$ yaitu $\delta_{\mathbf{C}} 20.6(\mathrm{C}-12) ; 20.9(\mathrm{C}-15) ; 22.0(\mathrm{C}-$ 14); 27.7 (C-13); 52.6 (C-8) dan 35.3 (C-7) ppm, 8 sinyal karbon $\mathrm{C}-\mathrm{sp}^{2}\left(\delta_{\mathrm{C}} 123.9(\mathrm{C}-10)\right.$; 126.6 (C-2, C-6); 129.4 (C-3, C-5); 135.8 (C4); 143.6 (C-1); 155.2 (C-11) ppm), sinyal karbon dari gugus karbonil $(\mathrm{C}=\mathrm{O})$ pada $\delta_{\mathbf{C}}$ 199,6 ppm.

Hasil analisis data 1D NMR didukung oleh data 2D NMR yaitu data HSQC ditunjukkan oleh Gambar 1 dan data HMBC ditunjukkan oleh Gambar 2 serta Tabel 1. Analisis data HSQC (Gambar 1) menunjukkan adanya korelasi satu ikatan sinyal proton $\left(\delta_{\mathrm{H}}\right)$ dengan sinyal karbon $\left(\delta_{\mathbf{C}}\right)$ dari empat gugus metil yaitu 1.27 dengan $22.0 ; 1.88$ dengan $27.7 ; 2.13$ dengan 20.6; 2.33 dengan 20.9. Adanya gugus metilen $\left(-\mathrm{CH}_{2}\right)$ ditunjukkan oleh korelasi 2.66 dengan 52.6, sedangkan korelasi 6.05 dengan 123.9 merupakan gugus alkena. Sinyal proton aromatis 7.13 berkorelasi dengan sinyal karbon 126.6 dan 129.4. Selanjutnya untuk mengetahui posisi gugus metil dan gugus karbonil dapat dilihat pada data HMBC (Gambar 2 dan Tabel 1). Berdasarkan hasil analisis data 1D, dan 2D NMR, maka dapat disimpulkan bahwa senyawa 1 hasil isolasi adalah senyawa golongan terpenoid, dari kelompok sesquiterpen yang dikenal sebagi artumeron (Gambar 3).

Hasil analisis data NMR ar-turmeron juga dibandingkan dengan data dari literatur dan mempunyai kesesuaian dengan data NMR yang dilaporkan Mahulikara and Maneb (2006) dan Ying et al. (2015) disajikan dalam Tabel 2 dan struktur ar-turmeron seperti pada Gambar 3. Berdasarkan penelusuran literatur, penemuan senyawa ar-turmeron merupakan pertama kali pada tanaman $C$. soloensis Val. tetapi pernah ditemukan pada beberapa species curcuma lainnya. Ar-turmeron telah ditemukan pada $C$. longa, $C$. yunnanensis, $C$. rubescens Roxb (Lateef et al. 2016; Xiang et al., 2018; Widyowati et al., 2018). Ditemukannya senyawa ar-turmeron yang termasuk golongan seskuiterpen dalam ekstrak rimpang $C$. soloensis Val. semakin memperkuat bahwa golongan seskuiterpen merupakan komponen utama dalam genus Curcuma. Seskuiterpen telah ditemukan pada $C$. longa, $C$. zedoaria, $C$. xanthorrhiza, $C$. heyneana, $C$. aeruginosa, $C$. aromatic, C. elata Roxb, C. kwangsiensis var. nanlingensis, $\quad C . \quad$ nankunshanensis, $\quad C$. sichuanensis, C. yunnanensis, C. rubescens Roxb (Chen et al., 2016; Jeong et al., 2015; Diastuti et al., 2014; Srivilai et al., 2018; Xiang et al., 2018).

Tabel 1. Data HMBC senyawa 1

\begin{tabular}{cl}
\hline $\boldsymbol{\delta}_{\mathbf{H}}(\mathbf{p p m})$ & \multicolumn{1}{c}{$\mathbf{H M B C}_{\mathbf{C}}(\mathbf{p p m})$} \\
\hline 7.13 & $\mathrm{C}^{\prime} ; \mathrm{C} 6 ; \mathrm{C}^{\prime} ; \mathrm{C}^{\prime} ; \mathrm{C} 1^{\prime}$ \\
6.05 & $\mathrm{C} 1 ; \mathrm{C} 8, \mathrm{C} 4$ \\
3.30 & $\mathrm{C} 7 ; \mathrm{C} 5 ; \mathrm{C} 1^{\prime} ; \mathrm{C} 6$ \\
2.66 & $\mathrm{C} 7 ; \mathrm{C} 6 ; \mathrm{C}^{\prime} ; \mathrm{C} 4$ \\
2.33 & $\mathrm{C} 3^{\prime} ; \mathrm{C} 4$ \\
2.13 & $\mathrm{C} 1 ; \mathrm{C} 3 ; \mathrm{C} 2$ \\
1.88 & $\mathrm{C} 8 ; \mathrm{C} 3 ; \mathrm{C} 2$ \\
1.27 & $\mathrm{C} 6 ; \mathrm{C} 5 ; \mathrm{C} 1$
\end{tabular}

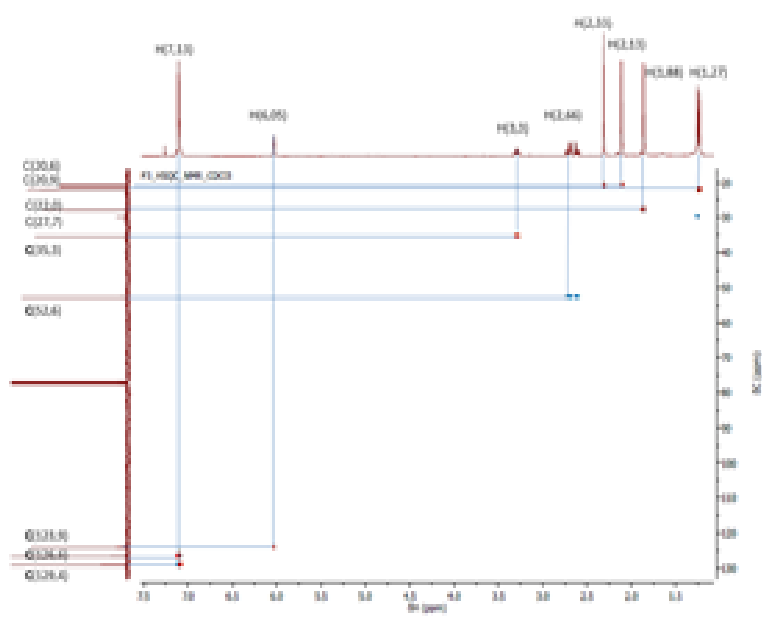

Gambar 1. Spektra HSQC senyawa 1

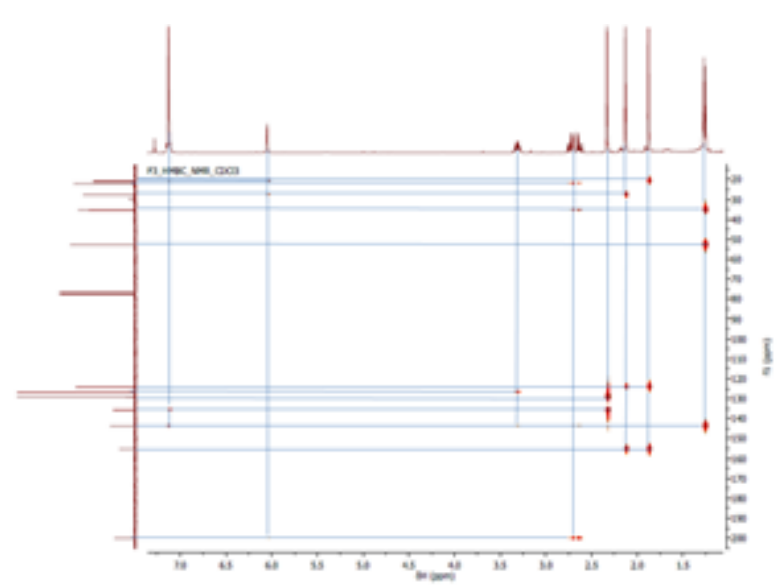

Gambar 2. Spektra HMBC senyawa 1 

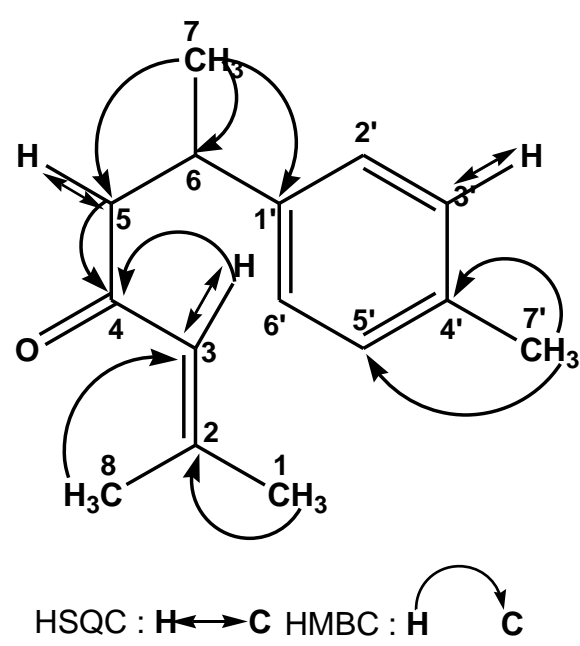<smiles>CC(C)=CC(=O)CC(C)c1ccc(C)cc1</smiles>

Gambar 3. Struktur ar-turmeron

Tabel 2. Data spektrum ${ }^{1} \mathrm{H},{ }^{13} \mathrm{C}$-NMR ar-turmeron

\begin{tabular}{|c|c|c|c|c|}
\hline \multirow{2}{*}{$\begin{array}{c}\text { Posisi } \\
\text { C }\end{array}$} & \multicolumn{2}{|c|}{$\delta_{\mathbf{H}}(\mathbf{p p m})$} & \multicolumn{2}{|c|}{$\delta_{\mathrm{C}}(\mathbf{p p m})$} \\
\hline & $1 *$ & 1 & $1 *$ & 1 \\
\hline 1 & - & - & 143.7 & 143.7 \\
\hline $2 / 6$ & $6.98(4 \mathrm{H}, s)$ & $\begin{array}{l}7.13(4 \mathrm{H}, \\
s)\end{array}$ & 126.6 & 126.6 \\
\hline $3 / 5$ & $6.98(4 \mathrm{H}, s)$ & $\begin{array}{l}7.13(4 \mathrm{H}, \\
s)\end{array}$ & 129.1 & 129.3 \\
\hline 4 & - & - & 135.5 & 135.8 \\
\hline 7 & $3.20(1 \mathrm{H}, m)$ & $\begin{array}{l}3.30(1 \mathrm{H}, \\
m)\end{array}$ & 35.3 & 35.3 \\
\hline 8 & $2.52(2 \mathrm{H}, m)$ & $\begin{array}{l}2.66(2 \mathrm{H}, \\
d d, J=6.05 ; \\
15.7 \mathrm{~Hz})\end{array}$ & 52.7 & 52.6 \\
\hline 9 & - & - & 199.8 & 199.7 \\
\hline 10 & $5.88(1 \mathrm{H}, s)$ & $\begin{array}{l}6.05(1 \mathrm{H}, \\
s)\end{array}$ & 124.1 & 123.9 \\
\hline 11 & - & - & 155.1 & 155.2 \\
\hline 12 & $2.06(3 \mathrm{H}, s)$ & $\begin{array}{l}2.13(s, \\
3 \mathrm{H})\end{array}$ & 20.7 & 20.6 \\
\hline 13 & $1.80(3 \mathrm{H}, s)$ & $\begin{array}{l}1.88(s, \\
3 \mathrm{H})\end{array}$ & 27.6 & 27.7 \\
\hline 14 & $\begin{array}{l}1.18(3 \mathrm{H}, d, \\
J=7.2 \mathrm{~Hz},)\end{array}$ & $\begin{array}{l}1.27(3 \mathrm{H}, \\
d, J=7,0 \\
\mathrm{~Hz},)\end{array}$ & 22.0 & 22.0 \\
\hline 15 & $2.25(3 \mathrm{H}, s)$ & $2.33(3 \mathrm{H}, s)$ & 20.9 & 20.9 \\
\hline
\end{tabular}

Senyawa 1*: ar-turmeron $\left(\mathrm{CDCl}_{3}, 400 \mathrm{MHz}\right)($ Ying et al., 2015; Mahulikar and Maneb, 2006)

Senyawa 1: ar-turmeron $\left(\mathrm{CDCl}_{3}, 400 \mathrm{MHz}\right)$

\section{SIMPULAN}

Seskuiterpen ar-turmeron (2-metil-6(4-metilfenil)hept-2-en-4-on) telah berhasil diisolasi dari ekstrak aseton rimpang $C$. soloensis Val. (temu glenyeh). Penemuan senyawa ini merupakan yang pertama kali untuk spesies $C$. soloensis Val.

\section{UCAPAN TERIMA KASIH}

Ucapan terimakasih disampaikan kepada Universitas Sebelas Maret atas bantuan dana PNBP melalui Penelitian Hibah Riset Fundamental dengan nomor kontrak: 1073/UN27.21/PP/2017.

\section{DAFTAR PUSTAKA}

Asghari G, Mostajeran A, Shebli M. 2009. Curcuminoid and essential oil component of turmeric at different stages of growth cultivated in iran. Research in Pharmaceutical Sciences. 4(1): 55-61.

Caiqin L, Weiqing C, Nan W, Jianchang J. 2018, Optimization of extraction of antioxidants from turmeric (Curcuma longa L.) using response surface methodology. Journal of Natural Sciences. 23(1): 063-069.

Chen JJ, Tsai TH, Liao HR, Chen LC, Kuo YH, Sung PJ, Chen CL, Wei CS. 2016. New sesquiterpenoids and antiplatelet aggregation constituents from the rhizomes of Curcuma zedoaria. Molecules. 21(10): 1385-1396.

Diastuti H, Syah YM, Juliawaty LD, Singgih M. 2014. Antibacterial activity of germacrane type sesquiterpenes from Curcuma heyneana Rhizomes. Indonesia. Journal of Chemistry. 14: 32-36.

Jantan I, Saputri FC, Qaisar MN, Buang F. 2012. Correlation between chemical composition of Curcuma domestica and Curcuma xanthorrhiza and their antioxidant effect on human lowdensity lipoprotein oxidation. Evidence-Based Complementary and Alternative Medicine. 1-10. 
Jeong CS, Shim SH. 2015. Antibiotic components from the rhizomes of Curcuma zedoaria. Natural Product Science. 21: 147-149.

Kato M, Nishikawa S, Ikehata A, Dochi K, Tani T, Takahashi T. 2017. Curcumin improves glucose tolerance via stimulation of glucagon-like peptide-1 secretion. Molecular Nutrition \& Food Research. 61(3): 1-20.

Lateef EA, Mahmoud F, Hammam O, Ahwany EE, Wakil EE, Kandil S, Taleb HA, Sayed ME, Hassenein H. 2016. Bioactive chemical constituents of Curcuma longa $\mathrm{L}$. rhizomes extract inhibit the growth of human hepatoma cell line (HepG2). Acta Pharmaceutica. 66: 387-398

Mahulikara PP, Maneb, RB. 2006 Application of Meldrum's acid in natural product synthesis. Synthesis of ar-turmerone and $\alpha$-curcumene. Journal of Chemical Research. 1(4): 15-18.

Mangunwardoyo, W., Deasywaty, Usia, T. 2012. Antimicrobial and identification of active compound Curcuma xanthorriza Roxb. International Journal of Basic \& Applied Sciences IJBAS-IJENS, 12 (1): 69-78.

Naksuriya O, Okonogi S, Schiffelers RM, Hennink, WE. 2014. Curcumin nanoformulations: a review of pharmaceutical properties and preclinical studies and clinical data related to cancer treatment. Biomaterials. 35: 3365-3383.

Nelson KM, Dahlin JL, Bisson J, Graham J, Pauli, GF, Walters, MA. 2017. The essential medicinal chemistry of curcumin. Journal of Medicinal Chemistry. 60: 1620-1637.

Pulido-Moran MM, Moreno JF, RamirezTortosa C, Ramirez-Tortosa MC. 2016. Curcumin and health. Molecules. 21(3): 264-286.

Shibuya H, Yoshihara M, Kitano E, Nagasawa M, Kitagawa I. 1999. Qualitative and quantitative analysis of essential oil constituents in various Zedoariae rhizoma (Gajutsu) by Gas Liquid Chromatography-Mass Spectro-metry. Journal of the Pharmaceutical Society of Japan. 3:212-216.

Simoh S, Zainal A. 2015. Chemical profiling of Curcuma aeruginosa Roxb. rhizome using different techniques of solvent extraction. Asian Pacific Journal of Tropical Biomedicine. 5(5): 412-417.

Srivilai J, Waranuch N, Tangsumranjit A, Khorana N, Ingkaninan K. 2018. Germacrone and sesquiterpeneenriched extracts from Curcuma aeruginosa Roxb. increase skin penetration of minoxidil, a hair growth promoter. Drug Delivery and Translational Research. 8(1): 140149.

Theanphong O, Mingvanish W, Kirdmanee C. 2015. Chemical constituents and biological activities of essential oil from Curcuma aeruginosa Roxb. rhizome. Bulletin of Health, Science and Technology. 13: 06-16.

Vitasari RA, Wibowo FR, Marliyana SD, Wartono MW. 2016. Isolation and identification of curcumin and bisacurone from rhizome extract of temu glenyeh (Curcuma soloensis. Val). IOP Conf. Ser.: Mater. Sci. Eng. 107012063.

Wikara T, Sulistiowaty A, Murhandini S, Usia T. 2016. Fingerprint study of Curcuma xanthorriza rhizome by High performance Thin Layer Chromatography (HPTLC). Jurnal Jamu Indonesia. 1(2): 9-14.

Xiang H, Zhang L, Xi L, Yang Y, Wang X, Lei D, Zheng X, Liu X. 2018. Phytochemical profiles and bioactivities of essential oils extracted from seven Curcuma herbs, Industrial Crops \& Products. 111: 298-305

Ying Z, Bowen P, Yang S. 2015. Preparation method of ar-turmerone reference 
substance in turmeric volatile oil, CN104478686A(https://patents.google .com/patent/CN104478686A/en).

Yuan T, Zhang C, Qiua C, Xia G, Wang F, Lin

B, Lia H, Chen L. 2017. Chemical constituents from Curcuma longa L. and their inhibitory effects of nitric oxide production, Natural Product Research. 32(16): 1887-1892. 